\title{
Entrevista al Dr. Héctor Fix Fierro
}

\section{Revista Abya-Yala Revista sobre Acceso a la Justicia y Derecho en las Américas, adscrita al departamento de Estudios Latinoamericanos de la Universidad de Brasilia.}

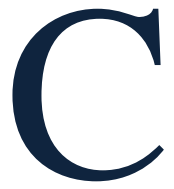

iudad de México, a 10 de diciembre del 2017. Entrevista realizada al doctor Héctor Fix-

Fierro quien es licenciado en Derecho por la Facultad de Derecho de la Universidad Nacional Autónoma de México, con Máster Internacional en Sociología Jurídica por el Instituto Internacional de Sociología Jurídica de Oñati, en el País Vasco, España, y doctor en Derecho por la Universidad de Bremen Alemania. Actualmente es investigador titular " $\mathrm{C}$ " de tiempo completo en el Instituto de Investigaciones Jurídicas de la UNAM", investigador nacional nivel III desde 2010 y profesor de "Sociología Jurídica" en la Maestría en Derecho de la Facultad de Derecho de la UNAM. Fue director del Instituto de Investigaciones Jurídicas de la UNAM entre 2006 y 2014.

Dra. Irene Juárez- Doctor, ¿podría comentarme sobre la historia de la sociología jurídica como área de investigación en el Instituto? ¿Cuándo inició y qué debates institucionales iniciales se tuvieron al respecto?

Dr. Héctor Fix Fierro- Creo que desde los años sesenta ha habido 
investigadores en el Instituto con algún interés en la sociología jurídica, aunque en esa época no había quién se dedicara de manera principal a cultivarla. Sé, por ejemplo, que durante su periodo como director del Instituto entre 1966 y 1978, el doctor Héctor Fix-Zamudio veía con interés este tipo de estudios y que le parecían importantes como complementarios de las investigaciones jurídicas tradicionales, pero en ese momento no encontró quién pudiera impulsarlos. Debo recordar que el Instituto publicó en 1984 la traducción de un estudio pionero del profesor alemán Volkmar Gessner sobre los conflictos sociales y la administración de justicia. El estudio se realizó a fines de los años sesenta y aunque ya había, como he dicho, interés en esta clase de investigaciones, no tuvo mayores repercusiones académicas ni políticas en ese momento. Creo que fue hasta fines de los años ochenta y principios de los noventa cuando varios amigos y compañeros de la generación tuvimos la oportunidad de estudiar fuera -en Francia y Alemania-con una idea más clara y precisa de la necesidad de hacer estudios socio-jurídicos, sobre todo de carácter empírico. En este sentido mencionaría yo al doctor Sergio López Ayllón, actual director general del Centro de Investigación y Docencia Económicas (CIDE), y al doctor Jorge Alberto González Galván, investigador en nuestro Instituto. Ellos dos realizaron estudios de sociología jurídica en Francia. En mi caso, realmente no cuento con una formación socio-jurídica amplia, sino que puedo considerar que la adquirí con mi tesis de doctorado.

En términos de la estructura y la organización del Instituto en la época en que fue director el doctor José Luis Soberanes (1990-1998), la sociología jurídica estaba incluida en el área de Historia y Filosofía del Derecho. Cuando llegó a la dirección el doctor Diego Valadés (1998-2006), se tomó la decisión de conformar un área independiente de Sociología del Derecho, la cual ha ido creciendo y subsiste hasta la fecha. Fue la época en que se iniciaron algunos estudios sobre la administración de justicia (en 2001, por ejemplo, se publicó una investigación amplia sobre los poderes judiciales locales) y lentamente empezó a formarse una masa crítica de investigadores e investigadoras que tenían la idea de impulsar la visión sociojurídica en la investigación. Me parece que al día de hoy ha dado frutos y resultados la apuesta que hicimos en los años noventa.

Hace algunos años, siendo yo director, estuvo de visita un profesor peruano interesado en el trabajo del Instituto. $\mathrm{Al}$ concluir su estancia me buscó para despedirse y yo le pregunté entonces qué era lo que más había llamado su atención. Me dijo que veía con mucha claridad un giro hacia la perspectiva 
sociojurídica en las actividades y las publicaciones del Instituto, percepción en la que yo coincidí. Esto podría estar motivado por la idea en muchos de nosotros de que, sin una perspectiva de cómo se insertan los cambios jurídicos en el entorno social, no vamos a entender más que una parte limitada de nuestro campo.

Dra. Irene Juárez- En relación a esto doctor, ¿cuáles considera que son las principales características de la sociología jurídica que se desarrolla en el Instituto?

Dr. Héctor Fix Fierro- Los estudios sociojurídicos conforman un campo muy amplio e interdisciplinario, cuyo común denominador sea quizá -como dice el profesor norteamericano Richard Abel-ocuparse de todo lo que tenga que ver con el derecho, menos las normas. Hay estudios propiamente jurídicos que incorporan algunos elementos jurídicos, pero también otros que se encuentran completamente en el área, sobre todo los de carácter empírico. Quiero recordar-porque no lo mencioné en la respuesta anterior que en 2004 se creó en el Instituto un área (ahora departamento) de investigación aplicada y opinión que coordina la maestra Julia Flores, quien es socióloga de formación. Esta área ha realizado una buena cantidad de estudios, de gran interés, que le dan todavía mayor presencia a la sociología jurídica en el Instituto. Se trata, entre otros estudios, de varias encuestas en materia de derechos humanos y discriminación, cultura constitucional, acceso a la justicia, etcétera, conformando un valioso cuerpo de datos y conocimientos que los juristas no hemos explotado de manera suficiente. Además, en años recientes se han incorporado al Instituto investigadoras e investigadores cuya formación inicial no es jurídica, pero que han descubierto que en el derecho hay mucho que aportar desde la sociología y las ciencias sociales en sentido amplio. Luego estamos los que tenemos de origen formación jurídica y que, con limitaciones teóricas y metodológicas, tratamos de incorporar en los estudios jurídicos tradicionales una perspectiva más amplia que tome en cuenta la realidad social.

Afortunadamente en estos últimos años, la cantidad de información y de datos que existen sobre la vida jurídica ha crecido muchísimo. Hace veinte o veinticinco años era mucho más difícil generar cierto tipo de información y ahora el Instituto Nacional de Geografía y Estadística y otras instituciones lo hacen de manera bastante completa y sistemática, de manera que el problema en la actualidad no es la falta de datos e información, sino más bien de la capacidad de explotarlos y de hacer algo útil con ellos.

Dra. Irene Juárez- ¿De qué manera se articula la perspectiva desarrollada por la 
sociología jurídica del Instituto con los debates internacionales vigentes?

\section{Dr. Héctor Fix Fierro- Existen} temas permanentes en la sociología jurídica: todo lo que tiene que ver con reforma judicial $y$, en general, con la transformación de las instituciones de justicia; lo que tiene que ver con los derechos, con la profesión jurídica, con la enseñanza del derecho. Son temas permanentes y transversales que, además, compartimos con otros países y otras instituciones, de manera que sí tenemos un diálogo, no tan intenso como quisiéramos o debiera ser, con investigadores e instituciones de otros países. En este sentido, es significativo que hace unos meses (junio de 2017) se realizara en México el Congreso Anual de la Law and Society Association, y claramente hubo una participación amplia e importante de los científicos sociales mexicanos, no sólo los juristas, en los temas del congreso; por eso fue una gran oportunidad de establecer y reforzar vínculos con académicos de otras partes.

Dra. Irene Juárez- En lo que respecta a la región latinoamericana, ¿con qué países se cuenta con vínculos y cuáles serían los temas principales de debate en los que los investigadores del Instituto adscritos a esta área están contribuyendo?
Dr. Héctor Fix Fierro- Yo insistiría en los temas que ya mencioné en la pregunta anterior. Quizá habría que agregar una problemática muy seria del continente: lo relativo a la seguridad pública en cuanto está vinculada con la justicia y los derechos. El control de la delincuencia es un tema que posiblemente tenga mayor antigüedad en países como Colombia, Brasil y Perú, pero que ahora tiene la mayor relevancia para México y por ello debería ser objeto de mayores intercambios.

Yo en lo personal estoy un poco aislado, por lo que no podría decir mucho más sobre la cuestión. Pero la generación más joven de sociólogos del derecho, los que están iniciando su carrera académica, claramente cuenta con una perspectiva más internacional y cultiva activamente sus vínculos con otros países.

A final de cuentas, las preguntas más amplias sobre las que debemos reflexionar y dar respuesta en nuestro continente serían las siguientes: ¿qué tan importante es el derecho? ¿qué funciones cumple en países como los nuestros?

Es evidente que no encontraremos las mismas características o las mismas funciones que se han estudiado en los Estados Unidos o en Europa Occidental. De todas modos, yo creo que el derecho sí es un elemento importante de la vida social e institucional latinoamericana, con todas las 
deformaciones y problemas que se quiera; que sí ha echado raíces entre nosotros el ideal de los procedimientos y de las instituciones gobernados por el derecho. Esto lo podríamos ver con más claridad si hacemos comparaciones con países más lejanos, como China y otros países asiáticos. Como han señalado varios sociólogos, finalmente América Latina es parte de "Occidente", de la cultura que llamamos occidental, aunque sea el "extremo Occidente" o el "otro Occidente", como se la ha llamado. Por eso, el Estado de derecho, el "imperio de la ley", sigue siendo parte de la lucha cotidiana de nuestras sociedades.

Dra. Irene Juárez- En su caso en particular ¿cuáles han sido los principales temas de interés en investigación y por qué? Encontramos que ha abordado la temática de la cultura judicial y también nos llama la atención lo tiene que ver con esto que mencionaba y con algunas cuestiones relacionadas con China.

Dr. Héctor Fix Fierro- En algo más de veinticinco años he cultivado principalmente dos temas. Uno es la reforma de la justicia. La reforma judicial es un tema que llegó un poco tarde a México en comparación con otros países de América Latina. Empecé a estudiar esta cuestión en 1993, por sugerencia del entonces director del Instituto, el doctor
José Luis Soberanes. La ocasión fue un seminario en Santiago de Chile en el que él iba a participar y al que me invitó a asistir. Mi primera aportación de fondo se concretó en mi tesis de doctorado, que se ocupó del concepto de eficiencia judicial desde una perspectiva sociojurídica. Hace veinticinco años no había casi estudios ni debates académicos sobre el tema, como lo observó Volkmar Gessner en una visita que hizo a México ese año, pero ello ha cambiado mucho si comparamos con el momento actual. Existe ya una masa crítica de investigadores con herramientas para estudiar fructíferamente estos temas desde la perspectiva de las ciencias sociales. Como derivación de la reforma de la justicia, he estudiado también a la profesión jurídica y la enseñanza del derecho, que eran también temas que prácticamente no existían en la investigación sociojurídica hasta hace algunos pocos años.

El segundo tema es el cambio jurídico en su relación con el cambio social. Desde esa época me pareció también -y en eso compartíamos la misma visión Sergio López Ayllón y yo-que nos encontrábamos en un momento de cambio jurídico acelerado (eran los tiempos en torno al Tratado de Libre Comercio con los Estados Unidos y Canadá) que nos exigía hacer una descripción inicial de esos procesos de cambio jurídico en su relación con las 
transformaciones políticas y económicas vinculadas a la globalización. En los noventa publicamos algunos trabajos que tienen, primero, un propósito descriptivo. Era como construir el primer piso de una casa, a partir de la escasa información que entonces existía. En esa época no sabíamos (y seguimos sin saber) cuántos abogados hay en México o quiénes estudiaban derecho y por qué. Esa información ya se empezó a generar y nos permite tener una imagen cada vez más completa del campo jurídico, sobre la cual es posible realizar luego estudios más sofisticados y profundos.

No obstante ese propósito descriptivo, también iniciamos un ejercicio de interpretación y consideramos que estábamos frente a una "transición jurídica" que no sólo implicaba un cambio acelerado de normas, procedimientos e instituciones, sino un nuevo papel social del derecho, lo que se ponía en evidencia en la nueva visibilidad y relevancia de los tribunales.

Esta transición no se podía entender, como ya dije, sin examinar la interacción con otras culturas jurídicas. Así, hace veinte años publicamos un trabajo sobre los paneles binacionales del capítulo XIX del Tratado de Libre Comercio como espacio de confrontación entre la cultura jurídica mexicana y la cultura jurídica estadounidense. Algunos años después, por influencia de otro colega, el doctor Arturo Oropeza, me empecé a interesar por el estudio de la cultura jurídica de China. Aunque esté lejana y pertenezca verdaderamente a otra matriz histórica e ideológica, conocer esa cultura jurídica permite entender mejor la propia, tanto en las diferencias, que son muchas, como en las convergencias, que sí existen. La discusión gira en torno a si se trata de una convergencia real o aparente, es decir, de si está surgiendo una sociedad moderna totalmente distinta a la que conocemos hasta ahora.

Estos son entonces los temas centrales de mi investigación, aunque la dinámica de trabajo del Instituto obliga en ocasiones a abordar temas más jurídicos, como los derechos humanos o el derecho constitucional. Aún en estos casos, yo trato de hacerlo con una perspectiva sociojurídica complementaria.

Dra. Irene Juárez- Doctor, conocemos la traducción del libro de Primera lección de sociología del derecho del profesor Vincenzo Ferrari. Nos podría comentar ¿por qué eligió este libro para hacer la traducción?

Dr. Héctor Fix Fierro- Realmente yo no elegí el libro. El proyecto de traducirlo deriva de una visita a México del profesor Ferrari, quien es el decano de los sociólogos del derecho en Italia y actual 
director del Instituto de Oñati, en el año de 2010. Aquí tiene amigos y colegas que lo apreciamos y por eso vino al Instituto a dictar una conferencia sobre su visión de la sociología jurídica a cincuenta años de haber iniciado sus estudios de derecho. En esa ocasión me obsequió la edición italiana de su libro y me expresó su interés de que pudiera traducirse al español. Le dije que con gusto podría hacerlo yo, aunque podría tomar algo de tiempo, dadas mis obligaciones de entonces.

Finalmente el libro apareció, publicado por el Instituto, en 2015. Como el profesor Ferrari conoce perfectamente el español, revisó antes con mucho cuidado la traducción, le hizo algunas observaciones y agregó algunas notas dirigidas al lector de habla española. Al final, espero que haya quedado satisfecho con la traducción y la publicación.

¿Por qué es importante la aparición del libro, si ya hay en nuestro país varios manuales recientes de introducción a la sociología jurídica? Además del prestigio del autor, al que ya me he referido, hay que tomar en cuenta que no existe un canon para la enseñanza de la sociología del derecho, como lo hay en materias jurídicas como el derecho civil o el derecho constitucional. Hay algunos autores y referencias que se han vuelto "canónicos" - como la obra de Émile Durkheim o Max Weber-, pero en lo demás las introducciones a la sociología jurídica son muy diversas, casi diría personales, según el autor y su origen académico. Entonces, resulta muy valioso ampliar más el abanico de opciones.

Dra. Irene Juárez- Finalmente, ¿cuáles considera que son los principales retos que enfrenta la sociología jurídica como área de investigación en México y particularmente en la que se desarrolla aquí en el Instituto?

Dr. Héctor Fix Fierro- Sin agotar la pregunta, veo primero que sería muy importante poder utilizar más la información que existe, pues siento que no la explotamos lo suficiente. Por ejemplo, tengo la impresión de que los estudios que se realizan en el Departamento de Investigación Aplicada y Opinión no son suficientemente conocidos y aprovechados por el resto del Instituto. Ahí hay un déficit.

Otro déficit es la falta de una agenda de investigación más amplia y sistemática. Hace bastantes años promoví una reunión con colegas de otros centros e instituciones, con la idea de generar una agenda de investigación en el área de la justicia, es decir, identificar los temas donde hacía falta investigar, para ir llenando esas lagunas. Debo confesar que no pasamos de esa primera reunión, pero en nuestro descargo hay que tomar en cuenta que los temas de investigación se van presentando según la 
actualidad de los problemas y la disponibilidad de recursos materiales y humanos para llevar a cabo los estudios. Aún así, pienso que siempre podríamos hacer algo más por cubrir de mejor manera este campo de investigación.

Aunque al final son las circunstancias y las necesidades del momento las que van guiando las agendas de investigación, y si bien esto no parece lo más deseable o satisfactorio, año con año van en aumento los estudios, de diversa especie, que se producen y se publican sobre la realidad jurídica en México. Yo imparto dos veces al año el curso de Sociología Jurídica en la Maestría en Derecho de la División de Estudios de Posgrado de la Facultad de Derecho de la UNAM y cada semestre, al actualizar la bibliografía, siempre encuentro uno o más estudios relevantes que incorporar. Eso es muy satisfactorio. Por eso creo que estamos viviendo un muy buen momento para la sociología jurídica en México.

Dra. Irene Juárez- Doctor le agradezco mucho la entrevista.

Dr. Héctor Fix Fierro- De nada, buenas tardes. 